\title{
Morphological, anatomical and physiological traits of Euryodendron excelsum as affected by conservation translocation (augmentation vs. conservation introduction) in South China
}

\author{
H. REN ${ }^{*}$, , H.L. YI*, Q.M. ZHANG*, J. WANG ${ }^{*}$ X.Y. WEN ${ }^{*}$, Q.F. GUO ${ }^{* *}$, and H. LIU**,**** \\ Guangdong Provincial Key Laboratory of Applied Botany, South China Botanical Garden, Chinese Academy of \\ Sciences, Guangzhou 510650, China* \\ Southern Research Station, USDA Forest Service, Asheville, NC 28804, North Carolina, USA** \\ Department of Earth and Environment, Florida International University, Miami, Florida 33199 USA ${ }^{* * *}$ \\ Fairchild Tropical Botanic Garden, Miami, Florida 33156 USA $^{* * * *}$
}

\begin{abstract}
Euryodendron excelsum is a rare and endangered evergreen tree in South China. We conducted two experimental translocations (augmentation and conservation introduction) on this species and assessed morphological, anatomical and physiological traits of leaves after translocation. The introduction plants showed smaller specific leaf area, less developed palisade tissues, smaller palisade/spongy tissue ratio, stomata density and anthocyanin content, lower values of maximal quantum yield of PSII photochemistry, photochemical quenching coefficient, net photosynthetic rate, light-saturated net photosynthetic rate, light-saturation point, but higher light-compensation point. These differences in traits help explain why augmented plants grew faster than introduced plants. We found that E. excelsum can adapt to wide ranges of light intensity and water availability, including conditions encountered at the introduction site. Our findings suggest that some endemic and endangered plants with narrow distribution may adapt to different habitat conditions by rapidly altering their morphological, anatomical, and physiological traits.
\end{abstract}

Additional key words: assisted colonisation; morphological response; physiological response; reintroduction.

\section{Introduction}

Species around the globe are disappearing at an unprecedented rate because of several factors including narrow distribution ranges, reproduction obstacles, overexploitation, and habitat degradation (Maschinski and Haskins 2012, Mounce et al. 2017). These factors are generally exacerbated by climate change. An important method of preventing species extinction is conservation translocation (Hoegh-Guldberg et al. 2008, Seddon 2010, IUCN 2013). Conservation translocations can be facilitated by the ex situ collection of endangered species in botanical gardens through the provision of propagules or individual plants (Ren et al. 2012). There are three main types of conservation translocation: augmentation, reintroduction, and conservation introduction (Menges 2008, Liu et al. 2015). In augmentation, plants are added to an existing population in order to increase the population size or genetic diversity. In reintroduction, individuals of a species are planted into an area formerly inhabited by the species. In conservation introduction, plants are moved into new areas that are not part of the historic distribution of the species (IUCN 2013, Ren et al. 2014, Liu et al. 2015).

The monitoring of plant reintroductions is currently inadequate (Godefroid et al. 2011, Maschinski and Haskins 2012, Liu et al. 2015). In particular, plant functional traits and their responses to translocation sites, though important to explain reintroduction success or failure (Ren et al. 2010, Catoni and Gratani 2013), are seldom studied (Godefroid and Vanderborght 2011, Ren et al. 2014).

\footnotetext{
$\overline{\text { Received }} 15$ November 2017, accepted 20 July 2018.

${ }^{+}$Corresponding author; phone: +86-20-37252916; fax: +86-20-37252831; e-mail: renhai@scbg.ac.cn

Abbreviations: AQY - apparent quantum yield; Chl - chlorophyll; $E$ - transpiration rate; EHZ - Ehuangzhang Nature Reserve; $\mathrm{F}_{0}$ - minimal fluorescence yield of the dark-adapted state; $F_{0}{ }^{\prime}-$ minimal fluorescence yield of the light-adapted state; $F_{m}-$ maximal fluorescence yield of the dark-adapted state; $F_{m}{ }^{\prime}$ - maximal fluorescence yield of the light-adapted state; $F_{s}-$ steady-state fluorescence yield; $F_{v} / F_{m}$ - maximal quantum yield of PSII photochemistry; ILUE - instantaneous light-use efficiency; In-Ds - Introduction-Dry season; In-Ws - Introduction-Wet season; IUCN - International Union for Conservation of Nature; LCP - light-compensation point; LSP - light-saturation point; NPQ - nonphotochemical quenching; $P_{\max }$ - light-saturated net photosynthetic rate; $P_{\mathrm{N}}-$ net photosynthetic rate; $R_{\mathrm{D}}$ - respiration rate; SCBG - South China Botanical Garden; WUE - instantaneous water-use efficiency; $\Phi_{\mathrm{PSII}}-$ photochemical quenching coefficient.

Acknowledgments: The authors thank Dr. Nan Liu and Mr. Zhifang Lin for valuable suggestions and thank Mrs. Chunqing Long, Mrs. Rufang Deng, and Mrs. Xiaoying Hu for index measurements. This research was supported by the National Natural Science Foundation of China (31570422), Guangzhou Science and Technology Program (201710010137), and the Guangdong Science and Technology Program (2016A030303044). Thanks are also due to Prof. Bruce Jaffee for English editing and constructive comments.
} 
Information on the physiological and morphological traits of rare and endangered plants could also be useful for both in situ conservation and ex situ conservation under climate change (Busch et al. 2011, Catoni and Gratani 2013).

Euryodendron excelsum H. T. Chang is an evergreen tree (Fig. 1) of the family Theaceae; the genus is monotypic. Worldwide, there are only about 100 individuals of this species, and these occur at ten isolated sites in Yangchun City, Guangdong Province, South China. Two populations in neighboring Guangxi Zhuang Autonomous Region have become extinct because of human destruction. $E$. excelsum is ranked as the second most endangered plant in China (Shen et al. 2007), listed on the first grade class protected plants in China (Shen et al. 2009), and classified as critically endangered by the International Union for Conservation of Nature (IUCN) (Barstow 2017).

Plants of E. excelsum are subject to habitat fragmentation, but showed a high level of genetic variations both within and between populations (Luo et al. 2005, Su et al. 2009). E. excelsum seeds are not dormant, with up to $70 \%$ germinate rates. The survival rate of cuttings is about 20\% (Shen et al. 2016). E. excelsum grows slowly, but arbuscular mycorrhizal fungi can increase seedling survival and growth (Shen and Wang 2011). The ecophysiological traits of E. excelsum and its reintroduction possibilities have not been studied yet.

In this study, we conducted two translocation experiments. One experiment involved augmentation of an existing population, and the other included conservation introduction. The latter can be treated as an ex situ collection as well as it is located in a botanical garden. We compared the morphological, anatomical, and physiological traits of E. excelsum plants at the augmentation vs. introduction sites. We hypothesized that E. excelsum plants can adapt to different environments by changing their morphological and physiological traits.

\section{Materials and methods}

Study area: The study was conducted simultaneously at two sites. One site was at the Ehuangzhang Nature Reserve, Yangchun City, Guangdong Province, China (hereafter referred to as EHZ, the augmentation site) and the other was at the South China Botanical Garden (hereafter referred to as SCBG, the conservation introduction site), Guangdong Province, South China. SCBG had a fragment of secondary forest similar to that found at $\mathrm{EHZ}$ where $E$. excelsum originally grew. This natural habitat at SCBG has been subject to minimum human disturbance. Based on the climate change report, the climate at SCBG is predicted to become warmer and wetter within the next 20 years (Zhou et al. 2013). We hope to establish an E. excelsum population at SCBG as an ex situ conservation collection and a measure to address the climate change challenge to the species.
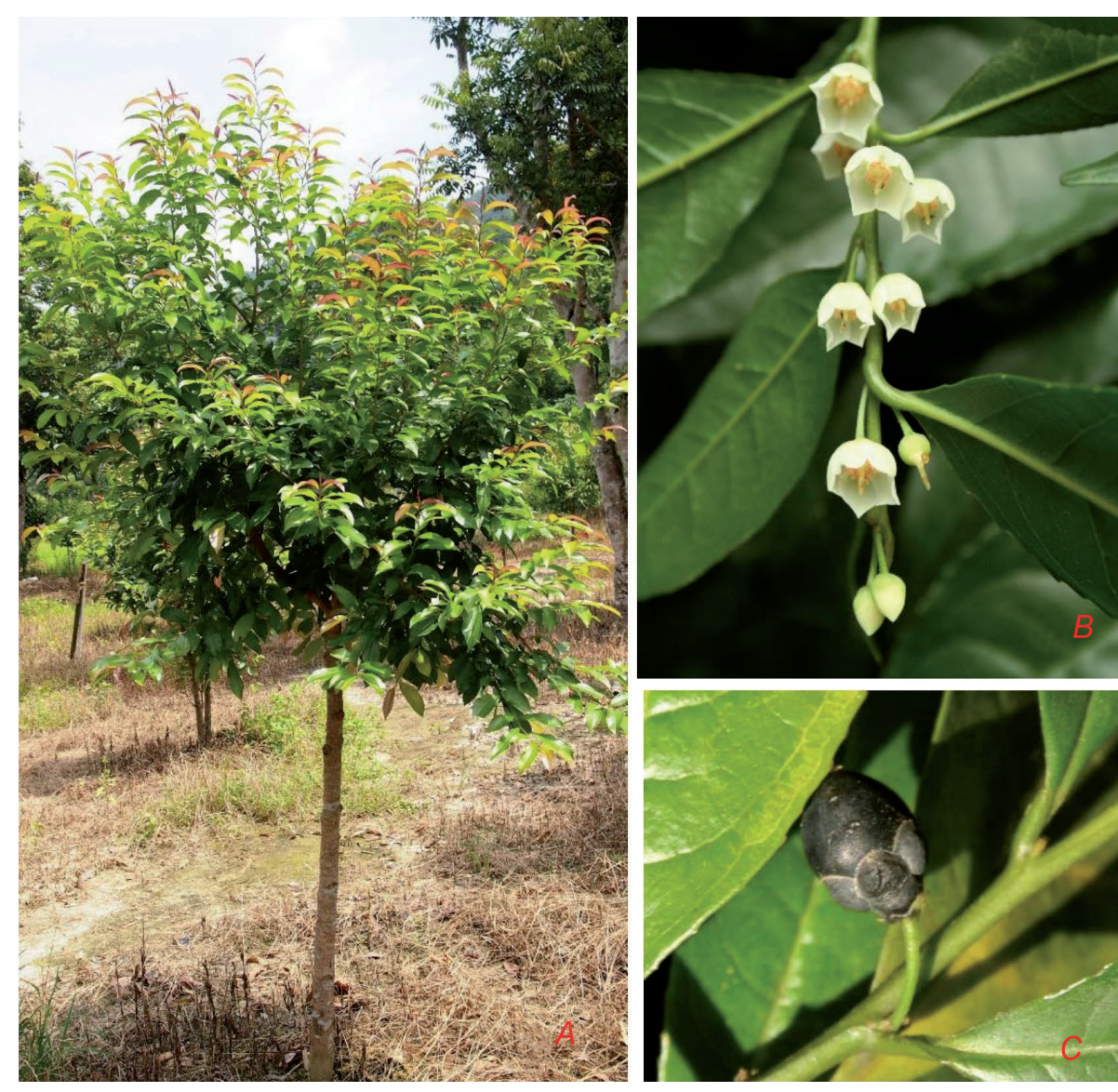

Fig. 1. A plant $(A)$, flower $(B)$, and fruit $(C)$ of Euryodendron excelsum. 
EHZ $\left(21^{\circ} 54^{\prime} 36^{\prime \prime} \mathrm{N}, 111^{\circ} 33^{\prime} 29^{\prime \prime} \mathrm{E}\right)$ in Yangchun City is an original distribution area of E. excelsum. It has a lower subtropical monsoon climate, with a mean annual temperature of $21.7^{\circ} \mathrm{C}$ and a total annual rainfall of 2,003 $\mathrm{mm}$ (Yangchun Meteorological Station). The elevation is about $160 \mathrm{~m}$. The soil is oxisolic with a high sand content in the upper layer and a $\mathrm{pH}$ ranging from 6.0 to 6.8 (Shen et al. 2009).

SCBG $\left(23^{\circ} 35^{\prime} 30^{\prime \prime} \mathrm{N}, 112^{\circ} 57^{\prime} 22^{\prime \prime} \mathrm{E}\right)$ is about $230 \mathrm{~km}$ outside of the original distribution area of E. excelsum. It also has a lower subtropical monsoon climate, with a mean annual temperature of $20.8^{\circ} \mathrm{C}$ and a total annual rainfall of 1,612 mm (South China Botanical Garden Meteorological Station). The elevation is about $58 \mathrm{~m}$. The soil is lateritic soil with a $\mathrm{pH}$ ranging from 4.5 to 6.0 . It is slightly cooler and drier than EHZ.

Plant material: The E. excelsum plants used in this study were propagated from seeds collected from populations at EHZ. These seeds were germinated and seedlings were grown in a nursery. The soil used in the nursery were collected from areas nearby wild E. excelsum plants. In April 2012, 20 healthy, 3-year-old plants of roughly the same size were selected. Ten of these were transplanted to EHZ, i.e., they were used to augment an existing population, and 10 were planted in the natural area at SCBG, i.e., they were introduced into a site that was outside of E. excelsum's indigenous distribution range. Hereafter, the transplants at EHZ are referred to as "augmentation plants" and those at SCBG as "introduction plants". The plants were transplanted with nursery soil at each site, and the plants were planted in $2.5 \mathrm{~m} \times 2.5 \mathrm{~m}$ grid systems in such a way that each plant was $2.5 \mathrm{~m}$ apart from its closest neighbors at both sites. Because E. excelsum is sun-tolerant, we cleared all plants from both sites before planting to eliminate competition from other plants. We watered the plants several times after planting, and then left them to grow naturally. Neither planting site was fenced, fertilized, or mulched. We measured the height of each plant immediately after planting and measured the height and assessed the survival of each plant once every six months until June 2015.

Leaf morphological and anatomical traits: In April (wet season) and October (dry season) of 2015, we used a leaf area meter (LI-3000, Li-Cor, USA) to measure the leaf area of three fully expanded leaves and three young leaves from each of the five randomly selected plants at each site. These leaves were then oven-dried $\left(65^{\circ} \mathrm{C}\right)$ to a constant mass. Specific leaf area was calculated as the ratio of leaf area to leaf dry mass $\left(\mathrm{cm}^{2} \mathrm{~g}^{-1}\right)$. This sampling likely had a little effect on plant growth and survival because these plants had large numbers of leaves.

Transverse sections from three fully expanded leaves and three young leaves from each of the five plants at each site were used to assess leaf anatomical traits as in detail below. The sections were examined and photographed with a light microscope (AX70, Olympus, Tokyo, Japan). Leaf epidermal structure was observed with a scanning electron microscope (JSM-6360LV, JEOL, Japan), using 15 leaves of each type (three mature and young leaves from each of the five plants at each site).

Leaf pigment contents: We harvested three young leaves and three mature leaves from each of five randomly selected plants at each site to analyze leaf pigment contents. To determine chlorophyll (Chl) and carotenoid (Car) contents, leaf discs $(0.6 \mathrm{~cm}$ in diameter $)$ were immersed in $80 \%$ acetone and were kept in the dark at $4^{\circ} \mathrm{C}$ for $5 \mathrm{~d}$. The light absorption of the extract was measured at 663,645 , and $440 \mathrm{~nm}$ with a UV-visible spectrophotometer ( $U V$ 3802, Unico, China), and the contents of Chl $a, \mathrm{Chl} b$, and Car were then calculated (Wang et al. 2016).

To determine the anthocyanin content, the leaves were cut into small pieces, immersed in methanol and $\mathrm{HCl}$ (99:1, v/v), and kept at $4{ }^{\circ} \mathrm{C}$ in the dark for $5 \mathrm{~d}$. Absorption of the extract was measured at 530 and $650 \mathrm{~nm}$ with a UVvisible spectrophotometer, and the anthocyanin content was calculated (Reddy et al. 1995, Wang et al. 2016).

Chl fluorescence parameters: One mature leaf and one young leaf from each of five randomly selected plants from each site were randomly selected. The following Chl fluorescence parameters of PSII were measured with a portable fluorescence spectrometer (PAM-2100, Heinz Walz, Effeltrich, Germany): the minimal fluorescence yield of the dark-adapted state $\left(\mathrm{F}_{0}\right)$, maximal fluorescence yield of the dark-adapted state $\left(\mathrm{F}_{\mathrm{m}}\right)$, minimal fluorescence yield of the light-adapted state $\left(\mathrm{F}_{0}{ }^{\prime}\right)$, maximal fluorescence yield of the light-adapted state $\left(\mathrm{F}_{\mathrm{m}}{ }^{\prime}\right)$, and steady-state fluorescence yield $\left(\mathrm{F}_{\mathrm{s}}\right)$. These leaves were dark-adapted for $30 \mathrm{~min}$ in leaf clamps before measurement. $F_{0}$ and $F_{m}$ were measured in the early morning before dawn, while other parameters were measured between 08:30-11:00 h (Wang et al. 2016). $\mathrm{F}_{0}$ was measured under a light intensity of $0.5 \mu \mathrm{mol}$ (photon) $\mathrm{m}^{-2} \mathrm{~s}^{-1}$, and $\mathrm{F}_{\mathrm{m}}$ was induced by $0.8-\mathrm{s}$ pulse of saturating light (PPFD of 2,700 $\mu \mathrm{mol} \mathrm{m}^{-2} \mathrm{~s}^{-1}$ ). The leaves were continuously irradiated with an actinic light of $138 \mu \mathrm{mol}$ (photon) $\mathrm{m}^{-2} \mathrm{~s}^{-1}$ for measurement of fluorescence quenching components. $\mathrm{F}_{\mathrm{m}}{ }^{\prime}$ was determined when the leaves were exposed to a second saturating pulse, and the steady-state fluorescence $F_{s}$ was then recorded within 5 min. To measure $\mathrm{F}_{0}{ }^{\prime}$, the leaves were irradiated with a weak 5-s far-red light. The maximum quantum yield of PSII photochemistry $\left[\mathrm{F}_{\mathrm{v}} / \mathrm{F}_{\mathrm{m}}=\left(\mathrm{F}_{\mathrm{m}}-\mathrm{F}_{0}\right) / \mathrm{F}_{\mathrm{m}}\right]$, photochemical quenching coefficient $\left[\Phi_{\mathrm{PSII}}=\left(\mathrm{F}_{\mathrm{m}}{ }^{\prime}-\mathrm{F}_{\mathrm{s}}\right) /\left(\mathrm{F}_{\mathrm{m}}{ }^{\prime}-\mathrm{F}_{0}{ }^{\prime}\right)\right]$, and nonphotochemical quenching $\left[\mathrm{NPQ}=\left(\mathrm{F}_{\mathrm{m}}-\mathrm{F}_{\mathrm{m}}{ }^{\prime}\right) / \mathrm{F}_{\mathrm{m}}{ }^{\prime}\right]$ were calculated (Souza et al. 2004).

Photosynthetic light-response curve and photosynthetic parameters: A photosynthetic light-response curve was measured under constant conditions $\left(\mathrm{CO}_{2}\right.$ concentration of $400 \mu \mathrm{mol} \mu \mathrm{mol}^{-1} ; 25^{\circ} \mathrm{C}$ ) with a portable photosynthesis system (LI 6400; LI-COR, Lincoln, NE, USA) on a sunny day. The photosynthetic capacity was measured at a PPFD of 1,$400 ; 1,200 ; 1,000 ; 800,500,300,150,100,50,30,15$, and $0 \mu \mathrm{mol} \mathrm{m} \mathrm{m}^{-2} \mathrm{~s}^{-1}$. The light-saturated net photosynthetic rate $\left(P_{\max }\right)$, respiration rate $\left(R_{\mathrm{D}}\right)$, apparent quantum yield (AQY), light-compensation point (LCP), light-saturation point (LSP), instantaneous water-use efficiency (WUE = 
$\left.P_{\mathrm{N}} / E\right)$, net photosynthetic rate $\left(P_{\mathrm{N}}\right)$, transpiration rate $(E)$, and instantaneous light-use efficiency (ILUE $\left.=P_{\mathrm{N}} / \mathrm{PAR}\right)$ were calculated by using the nonrectangular hyperbola model (SigmaPlot 10.0, Systat Software, San Jose, CA) of photosynthesis (Nijs et al. 1997, Wang et al. 2016).

Statistical analysis: When mean values were compared, a $t$-test (paired samples, two-tailed) in SPSS was used to assess the differences between young and mature leaves, augmentation and introduction, and dry and wet seasons. A $P \leq 0.05$ was considered statistically significant. Unless noted otherwise, means and standard deviations (SD) are presented.

\section{Results}

Plant survival rate and growth: After two years, survival rate of the transplanted plants was $100 \%$ at EHZ (the augmentation site) and $90 \%$ at SCBG (the introduction site). The initial height of all plants was $35.1 \pm 2.1 \mathrm{~cm}$. In June of 2015 (38 months after transplanting), the plants were taller at EHZ $(85.2 \pm 5.1 \mathrm{~cm})$ than that at SCBG $(56.5 \pm 8.3 \mathrm{~cm}$, mean $\pm \mathrm{SD})$. These results indicate that both survival rate and growth of augmentation plants were greater than that of the introduction plants.

Leaf morphological and anatomical traits: In all cases (dry $v s$. wet season, augmentation $v s$. introduction), leaf area was smaller, specific leaf area was greater, and leaf thickness was lesser in young leaves than hat of mature leaves (Table 1). Leaf area, specific leaf area, and leaf thickness of both young and mature leaves were lesser at the introduction site than that at the augmentation site in both dry and wet seasons (Table 1).

Although stomata density was greater for young than for mature leaves, the stomata of young leaves were smaller and were mostly closed (Fig. 2). The structure of the palisade tissue was developed in mature leaves but not in young leaves, and the ratio of palisade tissue/spongy tissue was lower in young leaves than that of mature leaves (Table 1).

Compared to the introduction plants, the augmentation plants had a greater specific leaf area, more developed palisade tissues, a greater palisade tissue/spongy tissue ratio, and a greater stomata density (Table 1).

Leaf pigment contents: For both introduction and augmentation plants in both wet and dry seasons, Chl and Car contents were lower and the anthocyanin content was higher in young than that in mature leaves (Table 2).

The Chl, Car, and anthocyanin contents were greater in the augmentation plants than that of introduction plants in both dry and wet seasons. The Chl content of the introduction plants did not significantly differ between dry and wet season, while the Chl content of augmentation plants was greater in the wet season than that in the dry season. The anthocyanin content was greater in the augmentation plants than that of introduction plants in the dry season (Table 2).

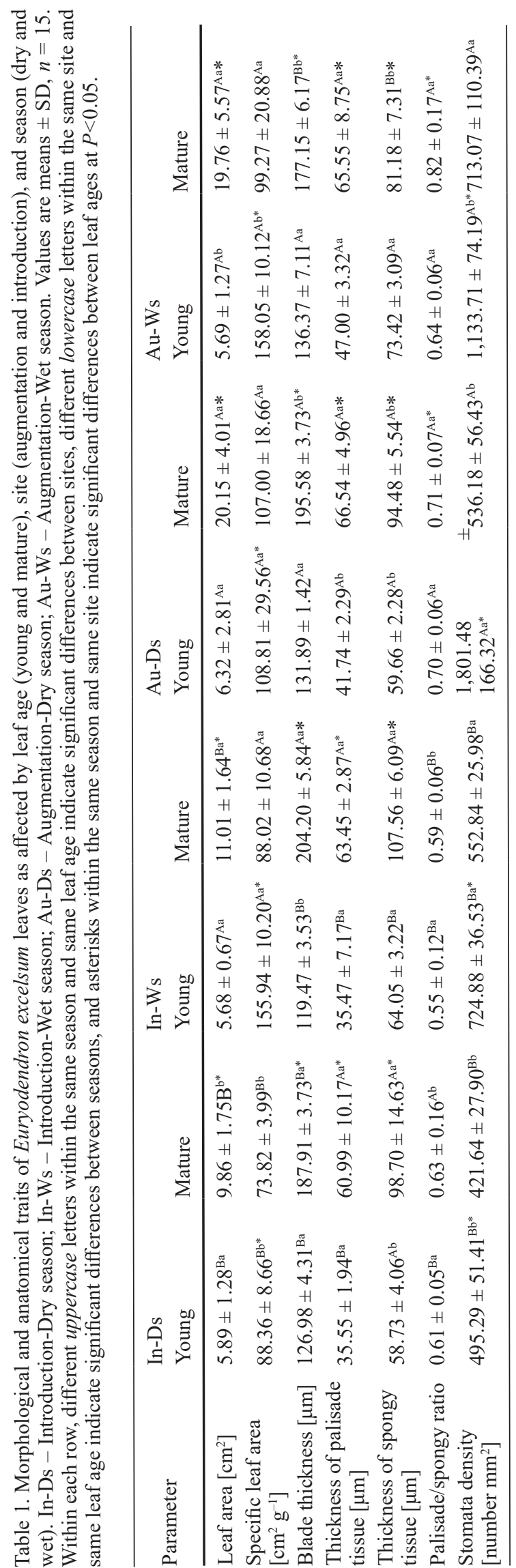



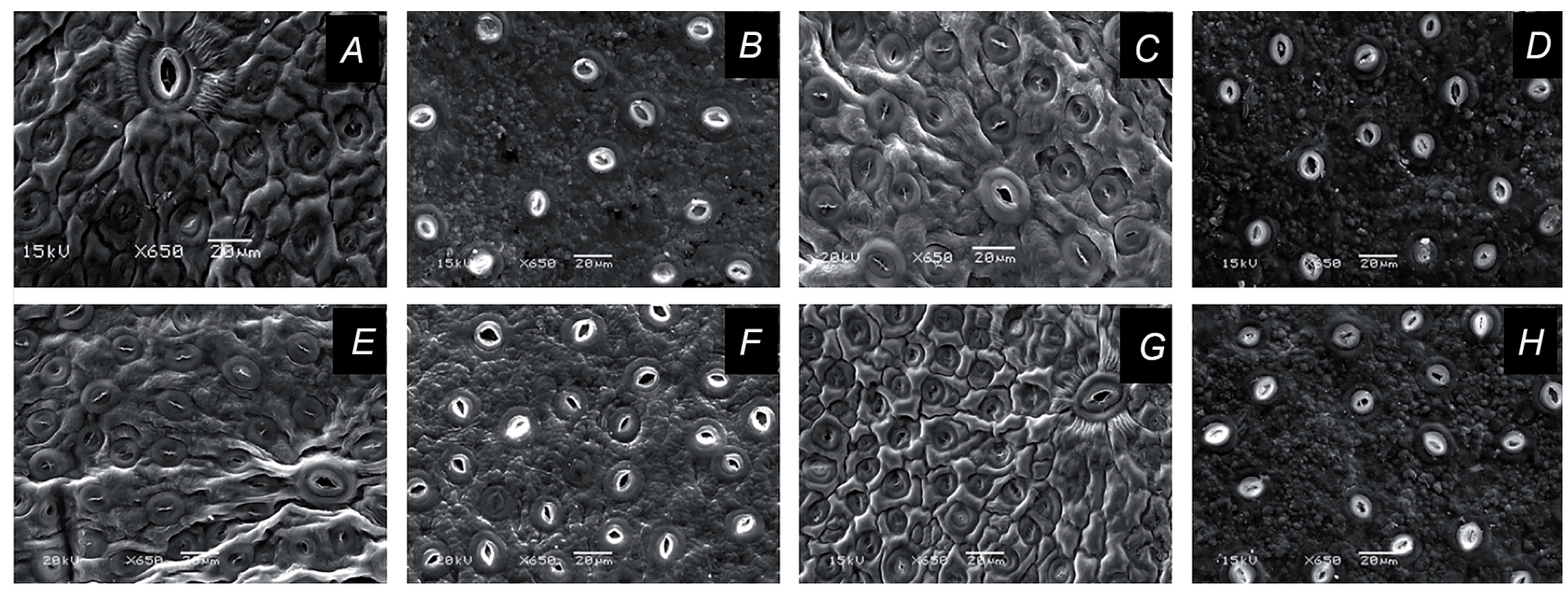

Fig. 2. SEM micrographs of stomata on leaves of augmentation and introduction Euryodendron excelsum plants. $(A)$ young leaf, introduction, dry season; $(B)$ mature leaf, introduction, dry season; $(C)$ young leaf, introduction, wet season; $(D)$ mature leaf, introduction, wet season; $(E)$ young leaf, augmentation, wet season; $(F)$ mature leaf, augmentation, wet season; $(G)$ young leaf, augmentation, dry season; $(H)$ mature leaf, augmentation, set season. Micrographs are at $650 \times$ magnification. Bars $=20 \mu \mathrm{m}$.

Chl fluorescence parameters: $F_{v} / F_{m}$ and $\Phi_{P S I I}$ values were lower but NPQ values were higher for young leaves than for mature leaves. $\mathrm{F}_{\mathrm{v}} / \mathrm{F}_{\mathrm{m}}$ and $\Phi_{\mathrm{PSII}}$ values were lower but NPQ values were higher in the dry season than that in the wet season (Fig. 3).

$\mathrm{F}_{\mathrm{v}} / \mathrm{F}_{\mathrm{m}}$ and $\Phi_{\text {PSII }}$ values of the PSII were significantly greater in the augmentation plants than that of introduction plants.

For introduction plants, the NPQ value was greater in the dry season than that in the wet season for young leaves, but the opposite was true for mature leaves.

Photosynthetic light-response curve and photosynthetic parameters: $P_{\mathrm{N}}$ increased rapidly as light intensity increased and then reached a steady state (Fig. 4). $P_{\mathrm{N}}$ was lower for young leaves than for mature leaves under different light intensities and reached saturation values at lower light intensities in young than that in mature leaves. Whether in the dry season or wet season, $P_{\mathrm{N}}$ of leaves of the same age was greater for augmentation plants than for introduction plants under the same light intensity (Fig. 4).

The average $P_{\max }$ and ILUE values of the young leaves of augmentation and introduction plants were similar in the dry and wet season and were lower than those of mature leaves (Table 3). Compared to the young leaves, mature leaves had lower LCP and higher LSP values.

$P_{\max }$ was lower in the young leaves than that of mature leaves of the augmentation plants in the wet season (Table 3). $P_{\max }$ was greater in the augmentation plants than that of for introduction plants. The mature leaves of augmentation plants had lower LCP and higher LSP values than the mature leaves of introduction plants.

The $P_{\max }$, ILUE, AQY, and LSP values of the mature leaves of augmentation plants were lower in the dry season than that in the wet season, while the opposite was true for LCP and $R_{\mathrm{D}}$ values (Table 3 ). The $P_{\max }$, ILUE, and AQY values of the mature leaves of introduction plants were greater in the dry season than in the wet season.
Like $P_{\mathrm{N}}$, transpiration rate $(E)$ increased with light intensity. For mature leaves of augmentation plants, $E$ was higher in the wet season than in the dry season (Fig. $5 A$ ). The maximum WUE was higher in mature leaves than that of young leaves (Fig. 5B). For mature leaves, WUE values were greater in the dry season than in wet season. $E$ values were greater for augmentation plants than that for introduction plants (Fig. $5 \mathrm{~A}$ ).

\section{Discussion}

The adaptive differences in functional traits of young vs. mature leaves: The changes in morphological and physiological traits between young and mature leaves of $E$. excelsum should help plants survive during augmentation and introduction. As leaves mature, the increase in specific leaf area, stomata density, and number of closed stomata, and the decrease in leaf area, leaf thickness, stomata size, and ratio of palisade tissue/spongy tissue should enable the plant to capture more light energy, adapt to drought, and increase their growth rate. These changes can also help reduce damage under strong light conditions.

The young leaves of E. excelsum are initially red. As the leaves mature, they gradually turn green, and their $\mathrm{Chl}$ and Car contents increase while their anthocyanin content decreases. Given that young leaves may experience significantly greater damage from herbivory and UV light than mature leaves, the red color of young leaves can be explained by two hypotheses. The photoprotection hypothesis suggests that red pigments (anthocyanins) protect against photoinhibition or photooxidation and thus allow a more efficient resorption of nutrients (Feild et al. 2001, Hoch 2001, Chen and Huang 2013). The animal-plant interaction hypothesis suggests that red leaves usually have better chemical defenses or poorer nutrition value than that of green leaves and that the red color signals these characteristics to herbivorous insects (Dominy 2002, Archetti 2009, Chen and Huang 2013). 

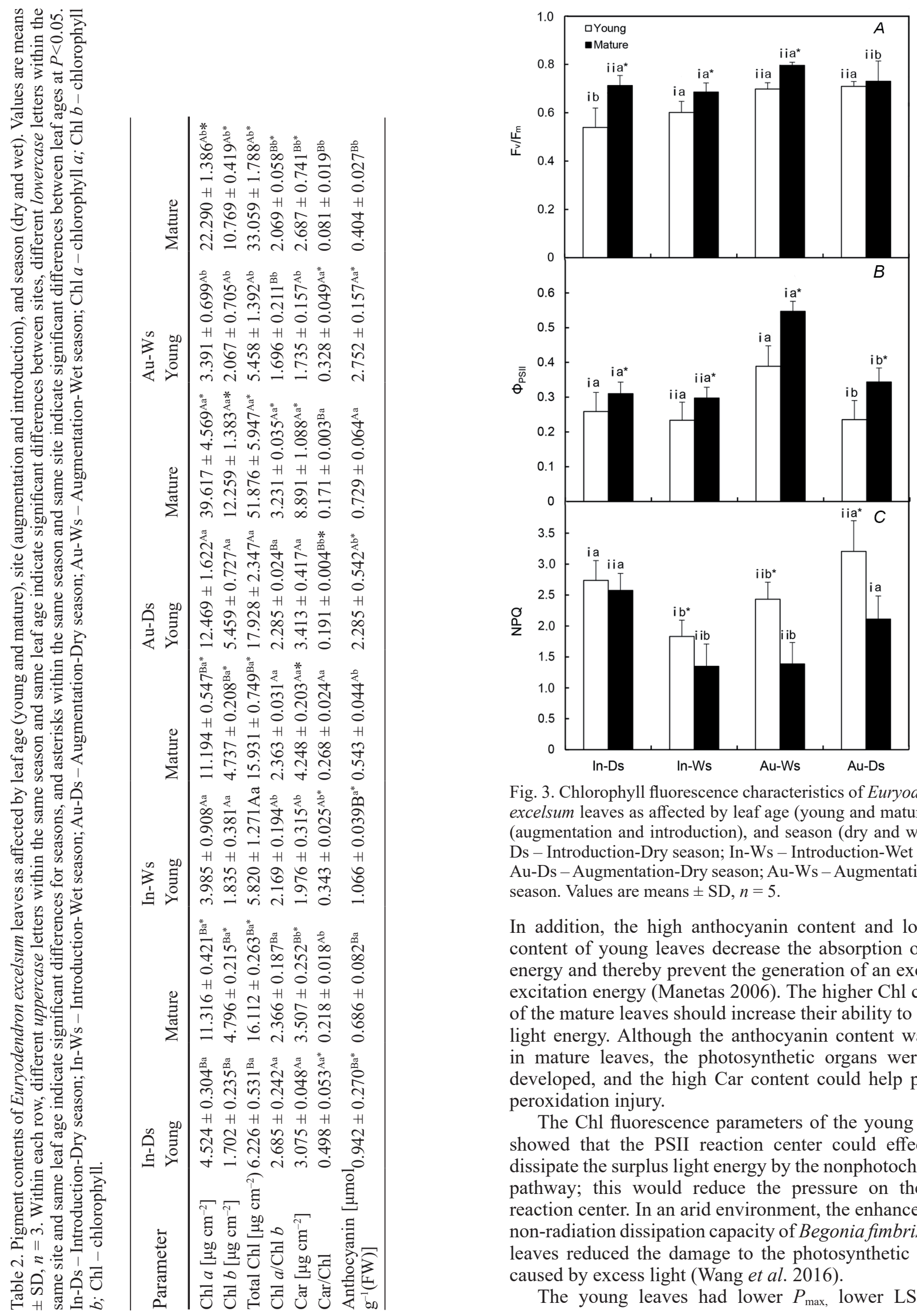

Fig. 3. Chlorophyll fluorescence characteristics of Euryodendron excelsum leaves as affected by leaf age (young and mature), site (augmentation and introduction), and season (dry and wet). InDs - Introduction-Dry season; In-Ws - Introduction-Wet season; Au-Ds - Augmentation-Dry season; Au-Ws - Augmentation-Wet season. Values are means $\pm \mathrm{SD}, n=5$.

In addition, the high anthocyanin content and low Chl content of young leaves decrease the absorption of light energy and thereby prevent the generation of an excess of excitation energy (Manetas 2006). The higher Chl content of the mature leaves should increase their ability to absorb light energy. Although the anthocyanin content was low in mature leaves, the photosynthetic organs were well developed, and the high Car content could help prevent peroxidation injury.

The Chl fluorescence parameters of the young leaves showed that the PSII reaction center could effectively dissipate the surplus light energy by the nonphotochemical pathway; this would reduce the pressure on the PSII reaction center. In an arid environment, the enhanced PSII non-radiation dissipation capacity of Begonia fimbristipula leaves reduced the damage to the photosynthetic organs caused by excess light (Wang et al. 2016).

The young leaves had lower $P_{\max }$, lower LSP, and 


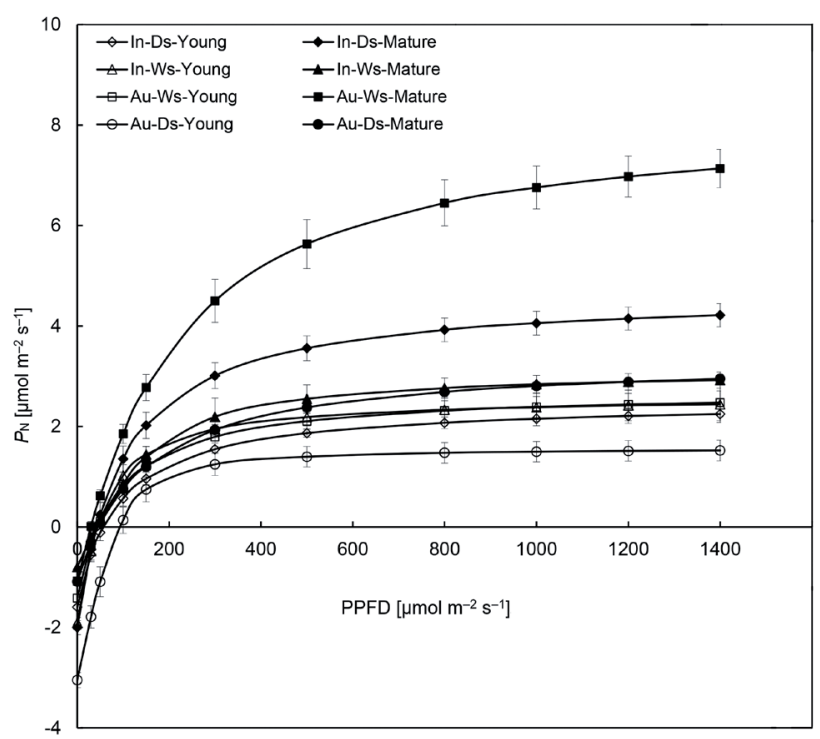

Fig. 4. Light-response curves of Euryodendron excelsum leaves as affected by leaf age (young and mature), site (augmentation and introduction), and season (dry and wet). In-Ds - IntroductionDry season; In-Ws - Introduction-Wet season; Au-Ds - Augmentation-Dry season; Au-Ws - Augmentation-Wet season. Values are means $\pm \mathrm{SD}, n=5$.

greater LCP values than that of the mature leaves. This could be related to the higher anthocyanin content in the young leaves. When plants are stressed by drought, high temperature, or strong light, they can protect the mesophyll by filtering and attenuating high-intensity blueviolet light in order to reduce photooxidation damage (Wang et al. 2016). The mature leaves had lower LCP and higher LSP values than the young leaves, which indicated that the mature leaves could use longer light-exposure times and a wider range of light wavelenghts than that of the young leaves, which would enable the mature leaves to accumulate more dry matter than the young leaves. In the dry season, the reduced transpiration rates for mature leaves were evidently a response to the arid environment.

Differences between functional traits in plants transplanted at augmentation vs. introduction sites: We found that the augmentation plants grew faster than introduction plants. Differences in the morphological and physiological traits between augmentation and introduction plants demonstrated the advantage of plants at its native site over the introduction site. They showed that the plants at the native habitat can capture more light, assimilate more $\mathrm{CO}_{2}$, and grow faster than those at the introduction site. The relatively slow growth of the introduction plants in the non-native habitat was accompanied by a decrease in a leaf size, which might be a response to the slightly cooler environment.

The Chl content and Car contents were higher in the augmentation plants than that of introduction plants in on both dry and wet seasons and in both young and mature leaves. Therefore, the ability to utilize light energy was greater for augmentation plants, especially under drought stress. The anthocyanin content, also greater in

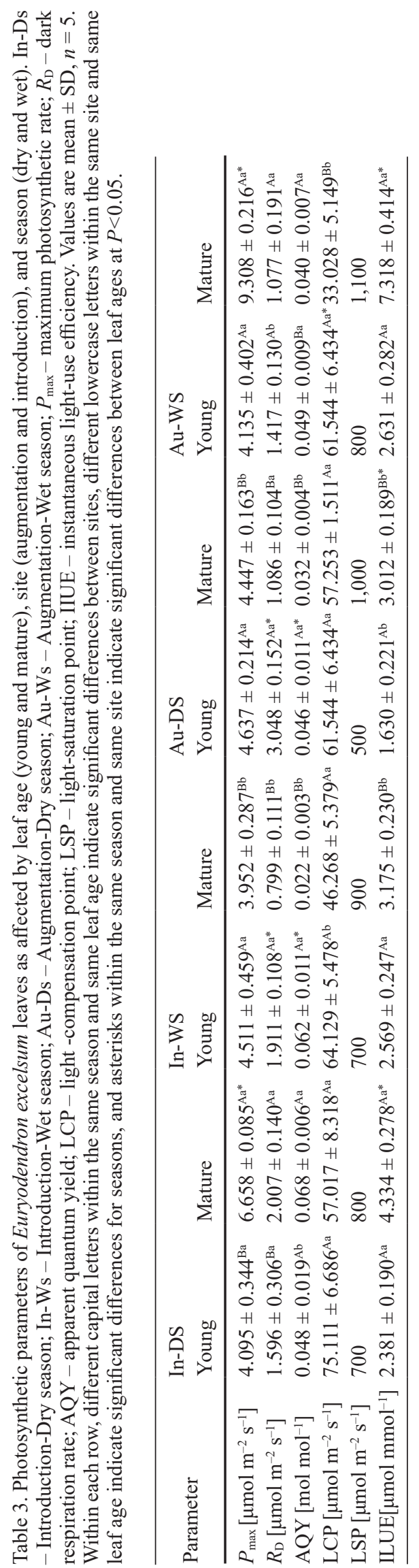




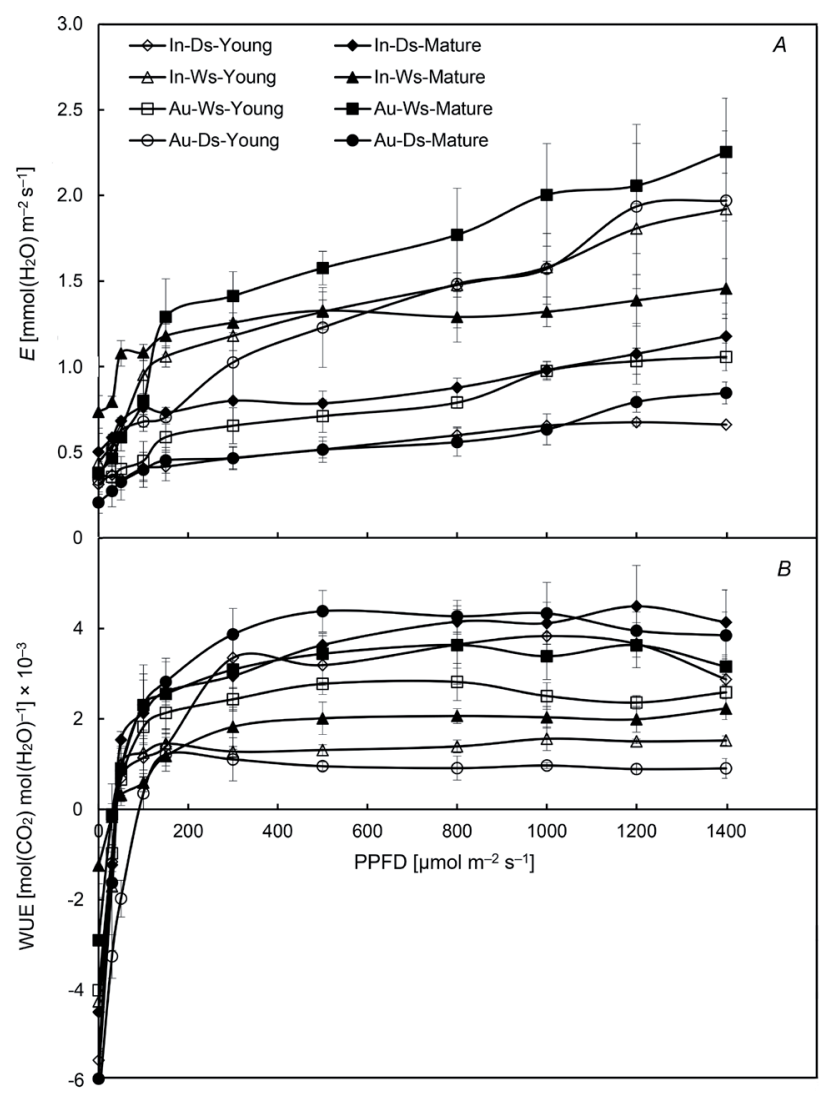

Fig. 5. Light-intensity responses of transpiration rate $(E, A)$ and instantaneous water-use efficiency (WUE, $B$ ) of Euryodendron excelsum leaves as affected by leaf age (young and mature), site (augmentation and introduction), and season (dry and wet). InDs - Introduction-Dry season; In-Ws - Introduction-Wet season; Au-Ds - Augmentation-Dry season; Au-Ws - Augmentation-Wet season. Values are means $\pm \mathrm{SD}, n=5$.

the augmentation than that of introduction plants, should reduce the damage to photosynthetic organs caused by excess light.

The difference in the photosynthesis parameters between the mature leaves of augmentation and introduction plants in the dry season indicated that water deficits experienced by the augmentation plants caused the decline in photosynthesis in the dry season. The introduction plants did not face a water deficit and did not experience a decline in photosynthesis in the dry season. These results indicate that E. excelsum can reduce its stomatal conductance and transpiration and can regulate its photosynthetic assimilation of carbon and its waterutilization strategy to cope with the drought environment during introduction.

Research on climate change has shown that, on average, global temperature would almost certainly increase in the future which could lead to reduced abundance and distribution or even extinction of many rare, endemic and endangered species (Maschinski and Haskins 2012, Liu et al. 2015, Mounce et al. 2017). Traditional conservation measures such as in situ protection, ex situ conservation, and reintroduction would continue to play an important role in rare plant conservation. Human-assisted plant movement, managed relocation or conservation introduction had been put forth as a strategy to conserve species threatened by the changing climate. The premise of conservation introduction is that threatened plants can be moved to locations where the future climate may be favorable for their persistence (Hoegh-Guldberg et al. 2008) and those threatened plants can adapt to a new habitat by changing functional traits (Li et al. 2015). However, some criticisms on conservation introduction argue that the relocated species may become invasive and have uncertain future in the new environment (Schlaepfer et al. 2009). Before we conducted conservation translocation, we had conducted species-specific habitat suitability assessments. Due to its slow growth, existing dispersal barrier, and low reproduction rate (Shen et al. 2007, 2009), E. excelsum maybe not become an invasive species in the near future. However, long-term experimentation and monitoring are clearly needed to provide the evidence for future debates.

Conclusion: Our results indicate that E. excelsum can be conserved via conservation and that augmentation may be more effective than introduction. The rapid changes in morphological and physiological traits in response to different habitat conditions also suggest that some endemic and rare species such as E. excelsum may have the ability to adapt to habitat changes. Conservation translocation can be used as a conservation tool to overcome plants' dispersal barriers under climate change.

\section{References}

Albrecht M.A., Guerrant E.O., Maschinski J. et al.: A long-term view of rare plant reintroduction. - Biol. Conserv. 144: 25572558, 2011.

Archetti M.: Classification of hypotheses on the evolution of autumn colors. - Oikos 118: 328-333, 2009.

Barstow M.: Euryodendron excelsum. The IUCN Red List of Threatened Species. e.T32348A2815634. Pp. 16. Fauna \& Flora International, Cambridge 2017.

Busch J., Dave R., Hannah L. et al.: Climate change and the cost of conserving species in Madagascar. - Conserv. Biol. 26: 408-419, 2011.

Catoni R., Gratani L.: Morphological and physiological adaptive traits of Mediterranean narrow endemic plants: The case of Centaurea gymnocarpa (Capraia Island, Italy). - Flora 208: 174-183, 2013.

Chen Y.Z., Huang S.Q.: Red young leaves have less mechanical defense than green young leaves. - Oikos 122: 1035-1041, 2013.

Dominy N.J.: Why are young leaves red? - Oikos 98: 163-176, 2002.

Feild T.S., Lee D.W., Holbrook N.M.: Why leaves turn red in autumn. The role of anthocyanins in senescing leaves of redosier dogwood. - Plant Physiol. 127: 566-574, 2001.

Godefroid S., Vanderborght T.: Plant reintroductions: the need for a global database. - Biodivers. Conserv. 20: 3683-3688, 2011.

Hoch W.A.: Physiological significance of anthocyanins during autumnal leaf senescence. - Tree Physiol. 21: 1-8, 2001.

Hoegh-Guldberg O., Hughes L., McIntyre S. et al.: Assisted colonization and rapid climate change. - Science 321: 345346,2008 
IUCN: Global Re-Introduction Perspectives: 2013. Further Case Studies from around the Globe. Pp. 213. Gland, Switzerland: IUCN/SSC Re-introduction Specialist Group, Abu Dhabi 2013

Li R.H., Zhu S.D., Chen H.Y.H. et al.: Are functional traits a good predict of global change impact on tree species abundance dynamics in a subtropical forest? - Ecol Lett. 18: 1181-1189, 2015.

Liu H., Ren H., Liu Q. et al.: The conservation translocation of threatened plants as a conservation measure in China: A review. - Conserv. Biol. 29: 1537-1551, 2015.

Luo X.Y., Tang G.D., Xu H. et al.: [Genetic diversity of three endemic and endangered species of the family Theaceae in Guangdong, China]. - Biodivers. Sci. 13: 112-121, 2005. [In Chinese]

Manetas Y.: Why some leaves are anthocyanic, and why most anthocyanic leaves are red. - Flora 201: 163-177, 2006.

Maschinski J., Haskins K.E.: Plant Reintroduction in a Changing Climate: Promises and Perils. Pp. 390. Island Press, Washington, DC 2012.

Menges, E.S.: Restoration demography and genetics of plants: when is a translocation successful? - Aust. J. Bot. 56: 187196, 2008.

Mounce R., Smith P., Brockington S.: Ex situ conservation of plant diversity in the world's botanic gardens. - Nat. Plant 3: 795-802, 2017.

Nijs I., Ferris R., Blum H.: Stomatal regulation in a changing climate: a field study using free air temperature increase (FATI) and free air $\mathrm{CO}_{2}$ enrichment (FACE). - Plant Cell Environ. 20: 1041-1050, 1997.

Reddy V.S., Dash S., Reddy A.R.: Anthocyanin pathway in rice (Oryza sativa L.): identification of a mutant showing dominant inhibition of anthocyanins in leaf and accumulation of proanthocyanins in pericarp. - Theor. Appl. Genet. 91: 301- 312, 1995.

Ren H., Jian S.G., Liu H.X. et al.: Advances in the reintroduction of rare and endangered wild plant species. - Sci. China Life Sci. 57: 603-609, 2014.

Ren H., Zhang Q.M., Lu H.F. et al.: Wild plan species with extremely small populations require conservation and reintroduction in China. - AMBIO 41: 913-917, 2012.

Ren H., Zhang Q.M., Wang Z.F. et al.: Conservation and possible reintroduction of an endangered plant based on an analysis of community ecology: a case study of Primulina tabacum Hance in China. - Plant Spec. Biol. 25: 43-50, 2010.

Schlaepfer M. A., Helenbrook W.D., Searing K.B.: Assisted colonization: Evaluating contrasting management actions (and values) in the face of uncertainty. - Trend Ecol. Evol. 24: 471-472, 2009.

Seddon P.J.: From reintroduction to assisted colonization: moving along the conservation translocation spectrum. - Restor. Ecol. 18: 796-802, 2010.

Shen S.K., Wang Y.H.: Arbuscular mycorrhizal (AM) status and seedling growth response to indigenous AM colonisation of Euryodendron excelsum in China: implications for restoring an endemic and critically endangered tree. - Aust. J. Bot. 59: 460-467, 2011.

Shen S.K., Wang Y.H., Wang B.Y. et al.: Distribution, stand characteristics and habitat of a critically endangered plant Euryodendron excelsum $\mathrm{H}$. T. Chang (Theaceae): implications for conservation. - Plant Spec. Biol. 24: 133-138, 2009.

Shen S.K., Wang Y.H., Zhang Y.J. et al.: [Advances research on the rare and endangered plant Euryodendron excelsum endemic to China]. - Chin. Wild Plant Res. 26: 1-4, 2007. [In Chinese]

Shen S.K., Wu F.Q., Yang G.S. et al.: Seed germination and seedling emergence of Euryodendron excelsum $\mathrm{H}$. T. Chang: implications for species conservation and restoration. - Plant Spec. Biol. 31: 233-239, 2016.

Souza R.P., Machado E.C., Silva J.A.B. et al.: Photosynthetic gas exchange, chlorophyll fluorescence and some associated metabolic changes in cowpea (Vigna unguiculata) during water stress and recovery. - Environ. Exp. Bot. 51: 45-56, 2004.

Su Y., Wang T., Sun Y. et al.: High ISSR variation in 14 surviving individuals of Euryodendron excelsum (Ternstroemiaceae) endemic to China. - Biochem. Genet. 47: 56-65, 2009.

Wang Y., Shao L., Wang J. et al.: Comparison of morphological and physiological characteristics in two phenotypes of a rare and endangered plant, Begonia fimbristipula Hance. Photosynthetica 54: 381-389, 2016.

Zhou G.Y., Peng C.H., Li Y.L. et al.: A climate change-induced threat to the ecological resilience of a subtropical monsoon evergreen broadleaved forest in south China. - Glob. Change Biol. 19: 1197-1210, 2013.

(C) The authors. This is an open access article distributed under the terms of the Creative Commons BY-NC-ND Licence. 